\title{
The role of thoracic duct lymph in gastrin transport and gastric secretion ${ }^{1}$
}

\author{
B. GUY CLENDINNEN ${ }^{2}$, DAVID D. REEDER, AND JAMES C. THOMPSON \\ From the Department of Surgery, The University of Texas Medical Branch, Galveston, Texas, and the \\ Department of Surgery, University of Bristol, Royal Infirmary, Bristol
}

SUMMARY The effect of thoracic lymph diversion on gastric secretion has been studied in dogs. In addition, the concentration of gastrin in thoracic duct lymph of nine dogs and two patients has been measured before and during antral stimulation with either food or acetylcholine. The secretory studies do not support the concept that there is a significant gastric secretagogue in thoracic duct lymph. The amount of gastrin carried in thoracic duct lymph as determined by radioimmunoassay is far less than that necessary to evoke a gastric secretory response.

The routes by which gastrin travels between its major site of production, the gastric antrum, and its target organs, in particular the gastric fundus, have not been fully determined. The premise that most or all of the antral gastrin is carried in the portal venous system through the liver to the systemic circulation is supported by the studies of Jackson, Reeder, and Thompson (1972) in which high levels of gastrin have been measured in the antral venous drainage of dogs.

Another possible channel for the transport of gastrin, the lymphatic system, has not been explored directly. Previous studies on the effect of interruption of flow of thoracic duct lymph on gastric secretion have given conflicting results. Evidence has been presented which suggests on the one hand that substances which inhibit gastric secretion are present in the lymph (Johnston and Code, 1960; Rudick, Gajewski, Pitts, Semb, Fletcher, Harkins, and Nyhus, 1965) and on the other hand that there are gastric secretagogues, perhaps gastrin, in the lymph (Johnston and Code, 1960; Kelly, Ikard, Nyhus, and Harkins, 1963; Rudick and Dreiling, 1967; Rudick, Fletcher, and Dreiling, 1968; Rudick, Fletcher, Dreiling, and Kark, 1968; Yakimets and Bondar, 1966 and 1967).

In the present study the concentrations of gastrin in thoracic duct lymph have been measured directly by radioimmunoassay during basal conditions and during strong antral stimulation, and the effect of

\footnotetext{
${ }^{1}$ Supported by grants from the National Institutes of Health, AM 15241, and General Clinical Research Centers Branch, RR-00073, and by a grant from the John A. Hartford Foundation, Inc.

${ }^{2}$ In receipt of medical research council grant G.970/480/C.

Received for publication 16 November 1972.
}

external diversion of lymph on the output of gastric acid has been reexamined.

\section{Materials and Methods}

Four groups of experiments were performed. Fourteen healthy alert adult mongrel dogs weighing $17-22 \mathrm{~kg}$ were used.

\section{GROUP 1}

In five dogs denervated gastric (Heidenhain) fundic pouches (HP) and antral fistulas were constructed and the dogs were allowed to recover for a period of at least four weeks. The dogs were then anaesthetized, a right thoracotomy was performed and the thoracic duct divided just above the diaphragm. The caudal end of the duct was cannulated with a polyvinyl tube that was brought through the chest wall, threaded subcutaneously for a distance of $10 \mathrm{~cm}$, reintroduced into the thoracic cavity, and then tied into the cephalic end of the thoracic duct. The catheter was positioned at a subcutaneous site that would permit easy access in the conscious dog, using local anaesthesia, for diversion of lymph from the caudal thoracic duct to the exterior. Lymph flow in the thoracic duct could be restored by reconnecting the polyvinyl tubing.

Tests were begun on the first postoperative day. The dogs were placed in Pavlov stands and a basal secretory state was verified in each dog (defined as less than $0.5 \mathrm{ml}$ secretion and less than $20 \mathrm{~m}$-equiv/l $\mathrm{HCl}$ in each of two 30-minute collections from the Heidenhain pouch). A balloon catheter was placed in the antrum through the fistula and $15 \mathrm{ml}$ of $1 \%$ acetylcholine ( $p \mathrm{H} \mathrm{7.0)}$ was instilled every 10 minutes for four and a half hours. The thoracic duct was 
intact during the initial one and a half hours of antral stimulation. During the second period of $\mathbf{9 0}$ minutes the cannula was disconnected and the lymph was diverted and collected. The catheter was then reconnected and the lymph flow was restored for a final one-and-a-half-hour period. The secretions from the Heidenhain pouch were collected every 30 minutes throughout the test. Volumes were recorded and acidity was measured by titrating with $0.1 \mathrm{~N}$ $\mathrm{NaOH}$ using phenol red indicator.

\section{GROUP 2}

In another group of five dogs fundic and antral fistulas were prepared after first transecting the stomach at the junction of the body and antrum as indicated externally by the incisura angularis. Stainless steel cannulas were inserted into the antrum and fundus of the stomach and were brought out through the abdominal wall. The thoracic duct was cannulated in continuity in the same manner as in the dogs in group 1. Testing was begun on the second postoperative day. After a basal secretory state had been established, a constant intravenous infusion of urecholine $(0.03 \mathrm{mg} / \mathrm{kg} / \mathrm{hr})$ was started and continued for five and a half hours. This dosage of urecholine was determined in pilot studies to be just subthreshold for stimulation of gastric secretion. Beginning one hour after the initiation of the urecholine infusion, the gastric antrum was irrigated through a balloon catheter every 10 minutes for the remainder of the experiment with $15 \mathrm{ml}$ of $1 \%$ acetylcholine as before. After one and a half hours of antral irrigation, the thoracic duct lymph was diverted for a period of one and a half hours. Lymph flow was then restored for a final one-and-a-halfhour period. Throughout the test, gastric secretions were collected at 30-minute intervals and the volume and acidity were measured. Five millilitre samples of lymph were taken from the thoracic duct of the dogs at the beginning of the experiment ( 0 hour), during infusion of urecholine alone (one hour), and during stimulation of the antrum with acetylcholine (two and a half, four and five and a half hours). The lymph samples were frozen, stored at $-20^{\circ} \mathrm{C}$, and were later measured for gastrin concentration by radioimmunoassay using a double antibody technique which has been described previously (Charters, Odell, Davidson, and Thompson, 1969; Jackson et al, 1972). From the time that the gastric fistula was constructed, fluid and electrolyte losses were measured and replaced until the end of the experiment.

\section{GROUP 3}

In four additional dogs the thoracic duct was cannulated in continuity as described above. On the second postoperative day samples of lymph and peripheral venous blood were taken from the alert fasting dogs for measurement of basal gastrin levels. Each dog was then fed a standard $400 \mathrm{~g}$ meat meal and samples of lymph and blood for gastrin measurement were taken at 10-minute intervals for one hour.

\section{GROUP 4}

Two patients with chronic fistulas of the thoracic duct were also studied. These patients were being prepared for renal transplantation by lymphocyte depletion (Fish, Sarles, and Remmers, 1970; Fish, Sarles, Remmers, Tyson, Canales, Beathard, Fukushima, Ritzmann, and Levin, 1969). Lymph and blood samples for gastrin measurement were obtained from each patient on four occasions before the first meal of the day and at 10,30 , and 60 minutes after.

\section{EXPRESSION OF VALUES}

In studies on the effect of lymph diversion on gastric secretion, the average 30-minute gastric acid output during the final hour of each of the three 90-minute test periods were compared in dogs in groups 1 and 2 . Acid secretion values are expressed as m-equiv $\mathrm{HCl} / 30 \mathrm{~min} \pm$ the standard error of the mean (SEM). The concentrations of gastrin in the thoracic duct lymph and peripheral venous serum are expressed in picograms (pg) per millitre. Statistical significance of changes in gastrin concentration or acid secretion was determined by Student's $t$ test where relevant.

\section{Results}

The amounts of acid secretion from the Heidenhain pouches in response to antral stimulation are shown in Figure 1. When the thoracic duct lymph was

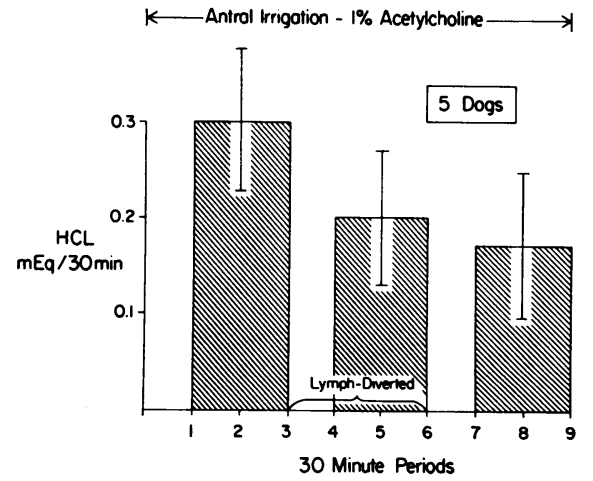

Fig. 1 Heidenhain pouch acid secretions during continuous antral stimulation with topical $1 \%$ acetylcholine. Values represent mean $( \pm S E M)$ of two 30 minute collections in each of five dogs. Thoracic duct lymph was diverted during the 90-minute period indicated. 


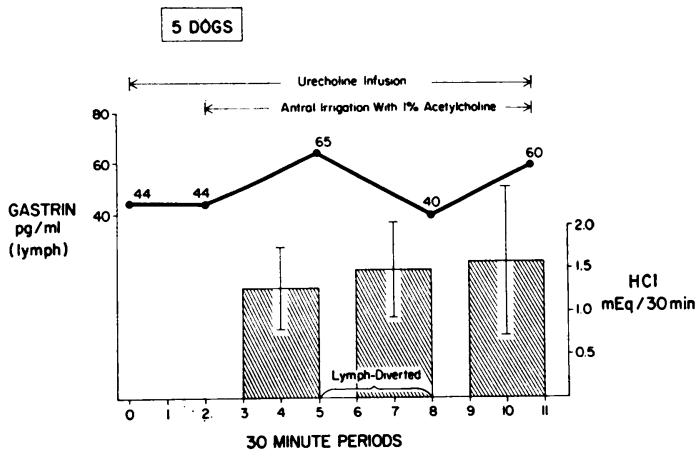

Fig. 2 Mean thoracic duct lymph gastrin concentrations (solid dots) and mean ( \pm SEM) 30-minute acid output from gastric fistulas (Bar graph) in five dogs. An intravenous infusion of urecholine was begun at time zero and continuous antral irrigation with $1 \%$ acetylcholine was initiated one hour later; both were continued throughout the experiments. Thoracic duct lymph was diverted to the exterior during the 90-minute period indicated.

diverted to the exterior there was a diminution in acid secretion from $0.30 \pm 0.08$ to $0.20 \pm 0.07$ m-equiv $\mathrm{HCl} / 30 \mathrm{~min}$. When thoracic duct continuity was restored and lymph was no longer diverted, however, there was a further diminution in acid secretion from the Heidenhain pouch to $0 \cdot 17 \pm$ 0.08 m-equiv $\mathrm{HCl} / 30 \mathrm{~min}$. There was no significant difference in acid output between any two of the three periods $(\mathrm{P}>0.05)$.

Acid secretion from the dogs with gastric fistulas increased from $1.25 \pm 0.49$ m-equiv $\mathrm{HCl} / 30 \mathrm{~min}$ in

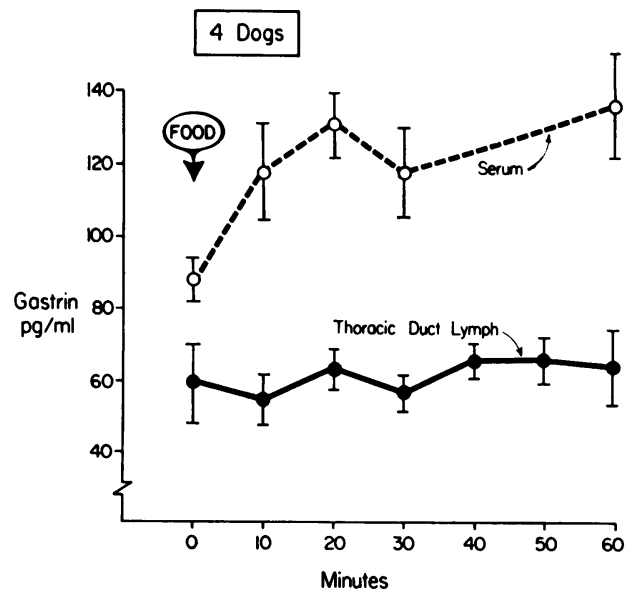

Fig. 3 Mean concentration of gastrin ( \pm SEM) before and after food in the serum and thoracic duct lymph of four dogs.

\begin{tabular}{|c|c|c|c|c|c|}
\hline \multicolumn{6}{|c|}{ Gastrin Concentrations (pg/ml) in Thoracic Duct Lymph } \\
\hline Dog. No. & Basal & One Hour & $\begin{array}{l}\text { Two-and- } \\
\text { a-half } \\
\text { Hours }\end{array}$ & $\begin{array}{l}\text { Four } \\
\text { Hours }\end{array}$ & $\begin{array}{l}\text { Five-and- } \\
\text { a-half } \\
\text { Hours }\end{array}$ \\
\hline 1 & 40 & 40 & 95 & 40 & 60 \\
\hline 2 & 40 & 60 & 60 & 40 & 70 \\
\hline 3 & 40 & 40 & 40 & 40 & 40 \\
\hline 4 & 60 & 40 & 90 & 40 & 90 \\
\hline 5 & 40 & 40 & 40 & 40 & 40 \\
\hline Mean & 44 & 44 & 65 & 40 & 60 \\
\hline
\end{tabular}

Table Gastrin concentrations in thoracic duct lymph before and at intervals during intravenous infusion of urecholine ${ }^{1}$

${ }^{1}$ Continuous antral irrigation with $1 \%$ acetylcholine was performed during the final four-and-a-half hours of the study.

the first period to $1.48 \pm 0.60$ m-equiv $\mathrm{HCl} / 30 \mathrm{~min}$ during the period of lymph diversion (Fig. 2). There was a further increase in acid output to $1.61 \pm 0.79$ m-equiv $\mathrm{HCl} / 30$ min after restoring lymph flow. There was no statistically significant difference in acid secretion between any two of these three test periods $(P>0 \cdot 1)$. The concentrations of gastrin in the lymph as measured by radioimmunoassay are given in Fig. 2 and in the Table. The limits of the assay were $40-1500 \mathrm{pg} / \mathrm{ml}$ and in many lymph samples there was insufficient gastrin to be measured, ie, the concentration was $<40 \mathrm{pg} / \mathrm{ml}$. For statistical purposes the level has been considered in these cases to be $40 \mathrm{pg} / \mathrm{ml}$. The mean fasting gastrin concentration was $44 \mathrm{pg} / \mathrm{ml}$. There was no apparent change in the gastrin concentrations in the samples taken after initiation of the urecholine infusion or during antral irrigation with acetylcholine (two and

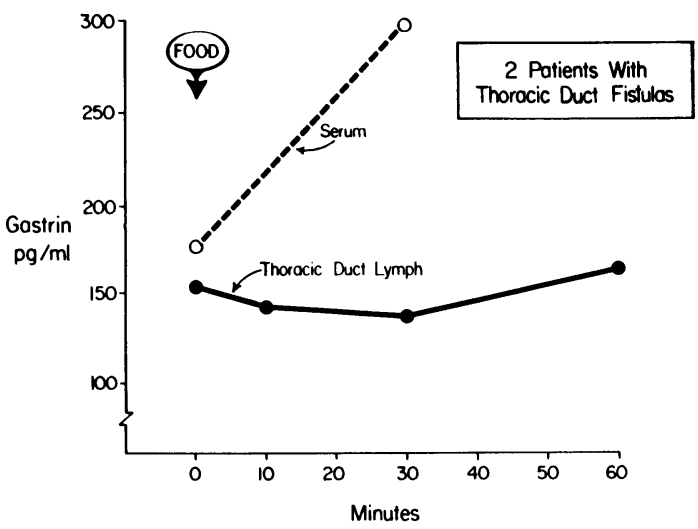

Fig. 4 Concentration of gastrin before and after food in serum and thoracic duct lymph. Data points are means of four separate experiments in each of two patients. 
a half, four, five and a half hours). Lymph flow varied in volume from 70 to $100 \mathrm{ml}$ per 90 -minute period of diversion in both groups of dogs.

The results from the four dogs of group 3 with fistulas of the thoracic duct alone are shown in Figure 3. The average fasting concentration of gastrin $( \pm$ SEM) in thoracic lymph was $60 \pm 10$ $\mathrm{pg} / \mathrm{ml}$ and showed no significant change after food. The fasting serum gastrin level was $88 \pm 5 \mathrm{pg} / \mathrm{ml}$ and this rose in the sample taken 20 minutes after food to $131 \pm 9 \mathrm{pg} / \mathrm{ml}(\mathrm{P}<0.01)$; the level remained significantly elevated for at least the one postprandial hour in which measurements were made.

The effect of feeding on serum and lymph gastrin levels in two patients with chronic fistulas of the thoracic duct are shown in Figure 4. The average concentration of gastrin in lymph was $153 \mathrm{pg} / \mathrm{ml}$ before food and $137 \mathrm{pg} / \mathrm{ml} 30$ minutes after food. In peripheral serum, on the contrary, there was a brisk rise in gastrin concentration from $175 \mathrm{pg} / \mathrm{ml}$ fasting to $297 \mathrm{pg} / \mathrm{ml} 30$ minutes after food.

\section{Discussion}

The experiments reported here were designed to determine by bioassay the presence or absence of a gastric secretagogue in thoracic duct lymph and to measure directly, by radioimmunoassay, the concentration of endogenous gastrin transported in thoracic duct lymph. In the first group of dogs a decrease in gastric secretion from denervated gastric pouches followed diversion of thoracic duct lymph, but restoration of flow did not cause acid output to rise. In the dogs with innervated gastric fistulas, acid output increased slightly during both the diversion and postdiversion periods, but again the change was not significant. These results are evidence against the presence of any gastric secretagogue of significance in the lymph.

These results are difficult to reconcile with those of other workers. One previous study (Johnston and Code, 1960), in which the presence of both inhibitory and stimulatory factors were reported in fasting and postprandial lymph, depended upon the reinfusion of homologous but not autologous lymph, and immune reactions were encountered which may have impaired the results. In addition, lymph was collected in heparin which has been shown to inhibit gastric secretion (Thompson, Lerner, Tramontana, and Miller, 1966). Although lymph was also collected in heparin in the study of Kelly et al (1963), in this case intravenous infusion of autologous postprandial lymph caused significant stimulation of secretion when given rapidly. Since this response was abolished when lymph collected after antrectomy was infused, the authors suggested that the secretagogue might be gastrin. Further studies on fractionated autologous lymph by Rudick and his colleagues (Rudick et al, 1965, 1966) indicated the presence of an inhibitory factor in fasting lymph which was not apparent in postprandial lymph, the latter having neither inhibitory nor stimulatory activity. These authors suggested that a gastric secretagogue released by feeding overshadowed the inhibitor.

Yakimets and Bondar $(1966,1967)$ studied the effects of lymph depletion in dogs before and after feeding. A significant drop in gastric secretion with diversion of lymph was found, but the experiments were performed under anaesthesia which may have depressed gastric secretion. These workers did not study the effects of reinfusing the lymph into the dogs.

Rudick et al (1968) reported an experiment similar to the one with the first group of dogs in the present study and found a drop in gastric secretion of acid on diversion of the thoracic lymph during topical antral stimulation. They found, contrary to our results, that restoration of the flow of lymph resulted in a rise in the level of gastric secretion to almost its original level. The latter part of the experiment was reported for only two dogs but was supported by previous observations on the effects of reinfusion of diverted lymph (Rudick and Dreiling, 1967) and by investigation of the effects on denervated gastric (Heidenhain) pouches of diversion of lymph during feeding (Rudick et al, 1968). With food as the antral stimulant they found that diversion of thoracic lymph reduced the output of acid from a denervated pouch by $59 \%$. Four weeks later, a time at which it was assumed that all lymphatic fistulas had clotted and lymph flow had been restored to normal, the output of pouch acid had returned to its original state. This experiment, however, is difficult to interpret because gastric secretagogues elaborated during the intestinal phase of gastric stimulation were probably influencing the pouch.

An average rate of lymph flow of $1 \mathrm{ml} / \mathrm{min}$ (approximately $50 \%$ more than that reported by Rudick et al, 1968) was found in our experiments. Despite lymphaticovenous anastomotic channels and variations in the number of trunks of the thoracic duct, it is probable that all but an insignificant amount of lymph was diverted, as a siphoning effect was used and this was seen to collapse the cisterna chyli at the time of operation.

The threshold dose of exogenous gastrin necessary to initiate secretion from an innervated fundic pouch in dogs is 171 nanograms $/ \mathrm{kg} / \mathrm{hr}$ (Cooke, 1967). If the estimated rate of thoracic duct lymph flow of $60 \mathrm{ml} / \mathrm{hr}$ is multiplied by the greatest concentration of gastrin measured in the lymph (65 
$\mathrm{pg} / \mathrm{ml}$ ) and corrected for a $20 \mathrm{~kg}$ dog, the rate of gastrin flow in thoracic duct lymph in our studies is about $195 \mathrm{pg} / \mathrm{kg} / \mathrm{hr}$ or approximately $1 / 1000$ of the amount of gastrin necessary to initiate gastric secretion. It would not appear that these small amounts of gastrin transported to the systemic circulation by the thoracic duct play an important role in control or alteration of the gastric secretory mechanism in dogs. Since food caused no rise in the gastrin levels in thoracic duct lymph in the two patients studied, it would appear also unlikely that lymphatic transport of gastrin is important in man. The results of the bioassay experiments with the first two groups of dogs support these conclusions.

\section{References}

Charters, A. C., Odell, W. D., Davidson, W. D., and Thompson, J. C. (1969). Development of a radioimmunoassay for gastrin. Arch. Surg., 99, 361-364.

Cooke, A. R. (1967). Comparison of acid and pepsin outputs from gastric fistula dogs in response to histamine, gastrin and related peptides. Gastroenterology, 53, 579-583.

Fish, J. C., Sarles, H. E., and Remmers, A. R., Jr. (1970). Thoracic duct fistulas in man. Surg. Gynec. Obstet., 131, 869-872.

Fish, J. C., Sarles, H. E., Remmers, A. R., Tyson, K. R. T., Canales, C. O., Beathard, G. A., Fukushima, M., Ritzmann, S. E., and Levin, W. C. (1969). Circulating lymphocyte depletion in preparation for renal allotransplantation. Surg. Gynec. Obstet., $128,777-787$.

Jackson, B. M., Reeder, D. D., and Thompson, J. C. (1972). Dynamic characteristics of gastrin release. Amer. J. Surg., 123, 137-142.

Johnston, I. D. A., and Code, C. F. (1960). Factors affecting gastric secretion in thoracic duct lymph of dogs. Amer. J. Physiol., 198, 721-724.

Kelly, K. A., Ikard, R. W., Nyhus, L. M., and Harkins, H. N. (1963). Gastric secretogogues in postprandial thoracic duct lymph. Amer. J. Physiol., 205, 85-88.

Rudick, J., and Dreiling, D. A. (1967). The transport of gastrin in lymph. Gastroenterology, 52, 1141.

Rudick, J., Fletcher, T. L., and Dreiling, D. A. (1968). Effects of lymph diversion on the gastric secretory response to endogenous gastrin. Amer. J. Physiol., 215, 370-374.

Rudick, J., Fletcher, T. L., Dreiling, D. A., and Kark, A. E. (1968). Influence of lymph diversion on the gastric secretory response to feeding. Proc. Soc. exp. Biol. (N.Y.), 128, 895-897.

Rudick, J., Gajewski, A. K., Pitts, C. L., Semb, L. S., Fletcher, T. L., Harkins, H. N., and Nyhus, L. M. (1965). Gastric inhibitors in fasting canine thoracic duct lymph. Proc. Soc. exp Biol. (N.Y.), 120,119-121.

Rudick, J., Gajewski, A. K., Pitts, C. L., Semb, L. S., Fletcher, T. L., Harkins, H. N., and Nyhus, L. M. (1966). Inhibition of gastric secretion by fractionated lymph. Elaboration of gastrone-like substance during digestive phases in dogs. Amer. Surg., 32, 513-520.

Thompson, J. C., Lerner, H. J., Tramontana, J. A., and Miller, J. H. (1966). Range of action of heparin in suppressing canine gastric acid secretion. Surg. Gynec. Obstet., 122, 264-268.

Yakimets, W. W., and Bondar, G. F. (1966). Thoracic duct lymph in the control of gastric secretion. Surg. Forum, 17, 307-309.

Yakimets, W. W., and Bondar, G. F. (1967). The effect of complete thoracic duct lymph diversion on gastric secretion in dogs. Canad. J. Surg., 10, 218.222. 